$\begin{gathered}\text { EPiC Series in Education Science } \\ \text { Volume 1, 2017, Pages 244-252 }\end{gathered}$
$\begin{gathered}\text { AUBEA 2017: Australasian Universities Build- } \\ \text { ing Education Association Conference 2017 }\end{gathered}$

\title{
Consultative Design as an Approach Towards Socially Sustainable Residential Aged Care
}

\author{
T. Hilaire ${ }^{1}$, K. Maund ${ }^{1}$, B. Swanepoel ${ }^{2}$ and J. Chapple ${ }^{2}$ \\ ${ }^{1}$ The University of Newcastle, Australia \\ ${ }^{2}$ Adventist Aged Care, Sydney \\ Trevor.Hilaire@Newcastle.edu.au
}

\begin{abstract}
Currently residential aged care (RAC) provides a solution to address ageing populations in many developed countries. Demand for RAC is predicted to increase as populations continue to age with the recurrent costs posing an increasing burden on society. The contribution the built environment can play to mitigate this potential burden is becoming increasingly important in the design and construction of RAC facilities. The theories of environmental psychology rationalise the relationship between the physical environment and the individual and impacts work stress/satisfaction. Work stress/satisfaction in RAC facilities has a direct influence on quality of care and can directly affect the residents' quality of life. This paper reports on a two stage study of design influences with the potential to impact upon the care team's work stress/satisfaction in RAC where the benefits of consultative design are identified. When compared to other facilities in the study the facility utilising a consultative design approach demonstrated more positive and less negative results for the design influences included. The consultative design approach reduced the potential for designers to copy and adapt a previous design, afforded universal ownership of the facility and optimised the building's impact on work stress/satisfaction. The approach formed the basis of an overarching process to ensure the necessary elements of the design influences framework can be appropriately incorporated into the built environment.
\end{abstract}

\section{Introduction}

Many developed countries are currently experiencing ageing populations as a result of a combination of circumstances (Alimoglua \& Donmezb, 2005). Currently residential aged care (RAC) facilities, provide a common solution to the problem. RAC facilities are purpose built or adapted 
buildings which, in Australia, comply with the National Construction Code (NCC) Classification 9c to accommodate aged persons with varying degrees of incapacity who are provided with nursing care, personal care and 24-hour staff assistance to evacuate the building during an emergency. However, as demand for RAC surges with the ageing population the initial and recurrent costs may become an increasing burden on society. The contribution the built environment can play to mitigate this potential burden is becoming increasingly important in the design and construction of RAC facilities.

The care is provided in RAC facilities by the "Care Team" consisting of a Registered Nurse, sometimes an Enrolled Endorsed Nurse and a body of Assistants in Nursing who carry out the day to day care procedures. The care team in RAC facilities are faced with a distinctive and specific set of circumstances including exposure to death and dying, working with cognitively impaired residents, coping with challenging behaviours, engaging in long term relationships with vulnerable residents and sometimes conflicting ideals between work responsibilities. These circumstances can result in a challenging and demanding role for the care team who provide for the needs of the residents (Edvardsson, Sandman, Nay, \& Karlsson, 2009).

The theories of environmental psychology rationalise the relationship between the physical environment and the individual (Aspinall, 2001). The interaction determines the role the physical environment plays in the contribution to stress or satisfaction. In a RAC work environment work stress/satisfaction can contribute to stress related work absences and staff turnover (Sinoo, Hoof, \& Kort, 2011) which impose a financial burden on the RAC organisation and the wider community.

Individual perceptions influence work stress/satisfaction resulting in varying effects on people. For example some sounds may represent noise to some individuals but are not noticed by others (Aspinall, 2001). This aspect forms a challenge when designing a RAC facility with optimal impact upon the care team's work stress/satisfaction.

Work stress/satisfaction in RAC facilities has a direct influence on quality of care (Hannan, Norman, \& Redfern, 2001) Frail, cognitively impaired residents rely heavily on the efforts of the Care Team (Castle, 2007). Higher levels of work stress can negatively impact upon the quality of care where higher levels of work satisfaction can increase the level of care and can advance the residents' quality of life.

The aim of this paper is to report on the benefits of consultative design identified within a previous two stage study of design influences with the potential to impact upon the care team's work stress/satisfaction in RAC. In reporting the previous findings the question of whether the consultative design process can be accommodated in the design process and if the consultative design process could provide an approach to providing more socially sustainable RAC facilities will be addressed. The objective of this paper is to demonstrate an alternative model for the design process to optimise facility design and provide opportunities to address work stress/satisfaction to address the "environmental fit" (Vischer, 2007) of facility users.

When viewed in the context of an ageing population with the associated economic, social and environmental implications allied to the impact on quality of care and the potential effect on quality of life in RAC, it would appear reasonable to design facilities with optimal impact upon the work stress/satisfaction of the Care Team.

\section{Literature Review}

RAC facilities provide unique design problems (Bakker, 2000) which should be approached on an individual basis to provide optimal solutions (Spanbroek, 2005). The design of a facility commences with a brief from the client and is interpreted by the facility designer as it progresses through the design process where design problems are resolved resulting in an optimal overall solution (Brawne, 1992). 
The pre-design phase of a construction project commences with the client brief and is the period in the project cycle where approximately $80 \%$ of the costs are determined (Tzortzopoulos et al., 2006). This phase underpins the balance of the project and can be the source of project success or problems (Smith et al., 2001).

Lam, Chan \& Chan (2010) found that the quality of the client's brief had a major impact on the success of the project with the development of the brief having the potential to impact project time, cost and quality with client organisations being perceived as having the most influence over the development of the brief (Othman et al., 2005). The brief communicates the client and stakeholder needs to the designers (Smith et al., 2001) and therefore clear identification of the requirements is a prerequisite to project success as there are many influences that can shift the focus of the brief ( $\mathrm{Yu}$ et al., 2008). A major influence can be the designer's interpretation of the brief in terms of their own personal experience, values, beliefs and perceptions whereby the resultant design fits their knowledge, expertise and experience (Restrepo \& Christiaans, 2004).

The methods used to create a design can vary between designers and one designer may also use more than one method simultaneously to arrive at a solution (Gray \& Hughes, 2001). Two of the major methods are outlined in this paper.

\subsection{Analysis - synthesis - evaluation}

The Royal Institute of British Architects (RIBA) (1980) summarises the design process into four phases being i) Assimilation, ii) General Study, iii) Development and iv) Communication. These four phases are reliant on the design problem and are not always in this sequence however, commencement is phase 1 and completion is phase 4 (RIBA, 1980).

This design process is supported by Lawson (2005) who argues that the process of increasing detail to meet the design brief involves i) analysis, the understanding and structuring of the problem, ii) synthesis, the creation of a number of possible solutions and appraisal, iii) appraisal the evaluation of the solutions before a decision can be made and iv) decision. (Lawson, 2005).

\subsection{Generator - conjecture - analysis}

In 1978 Jane Darke was investigating the image building designers had of the building user's expectations. In the course of the investigation it was found that the analysis-synthesis design process was not broadly used in practice. Darke (1978) found that building designers often adopted an idea early in the design phase and then attempted to manipulate the idea to work and go some way to solve the design problem. This system narrowed down the range of possible responses to the design problem and enabled designers to focus on a rapid solution, Darke adopted the term "primary generator" and described the system as "generator - conjecture - analysis" (Darke, 1979). Selection of the primary generator is based on the architect's subjective judgment or intuition (Rowe, 1987) (Darke, 1979) (Lawson, 2005).

Darke (1979) suggests that building designers often adopt a solution that is cognitively manageable to reduce the number of possible solutions to the design problem before detailed requirements have been worked out. Darke (1979) adopted the term "primary generator" and there is support for this idea by researchers like Brawne (1992), Ball, Evans and Dennis (1994) who refer to "position driven", Goel (1995) who uses "early crystallisation", Eckert \& Stacy (2000), Cross (2001) refers to "solution fixation", Restrepo \& Christiaans (2004) who use the term "early representation", Ball and Ormerod (2000) use "early fixation" and Visser (2006) who refers to "design kernels". These terms are used to describe the practice of selecting a design concept early in the design process and 
then adjusting and adapting that concept to the point where it has a fit with the design brief (Visser, 2006).

\section{Research Method}

The impact of consultative design in RAC was identified in a previous larger two stage study of design influences with the potential to impact upon the care team's work stress/satisfaction in RAC (Hilaire, 2016). Stage 2 of the previous larger project included a multi-case study of existing RAC facilities where the care team, managers and designers of each facility were interviewed in regard to the fit of the facility to the users and work practices. The RAC facilities in the previous larger study were selected from facilities designed post the Aged Care Act (1997) where management had responded to an invitation letter. Additionally the participants from the management team and the design team, present during the design process needed to be available. Participants from the care team comprised volunteers from within the facility. Semi-formal structured recorded interviews were conducted with participants from three groups in each case comprising management, care team and the designers. The interviews sought to investigate the participants experience and perception in regard to a number of "design influences" identified in literature and confirmed in Stage 1 of the previous larger project. Data analysis included coding and thematic analysis of the qualitative interview scripts assisted by the use of appropriate software. One case (Case 2) stood apart from the others as having significantly less negative comments and a greater number of positive comments regarding the design influences. Furthermore, all three groups interviewed for Case 2 (care team, management and designers) claimed ownership of the facility design. Firstly a review of the literature concerning the design process was undertaken. Principles and practices of the design process were then identified and reviewed in the context of Case 2. This paper focuses upon the design process for RAC facilities with a discussion of consultative process for Case 2 and the description of a model to integrate the beneficial aspects of the consultative 2 design process.

\section{Results}

The process of design used for Case 2 was very different to the design processes used for the other facilities in the previous larger study. The designers of the other cases in the previous study freely admitted during the interviews that the facilities were based on adaptions of previous designs. They prescribed to Darke's suggestion that designers do not always carry out a detailed analysis of the design problem and tend to adapt a previous project or parts of a previous project until there is an approximate fit (Darke, 1979). Darke termed this process "premature commitment" and has been further supported by Brawne (1992), Eckert \& Stacy (2000), Restrepo \& Christiaans (2004) and Visser (2006).

\subsection{Design Process Facility 2}

Whilst undertaking Stage 2, a multi-case study of existing RAC facilities in a two stage study of design influences in RAC (Hilaire, 2016), one case (Case 2) stood apart from the others where the participants from the care team and facility managers provided significantly less negative comments and a greater number of positive comments in regard to the suitability or "environmental fit" (Vischer, 2007) of the facility with users. 
An important facet of the design process was flagged in the Case 2 study with all participants related to that facility (care team, managers and designers) taking ownership of the design of the facility from the overall layout and external grounds to the internal finishes and decoration. Further investigation revealed a process of consultation with all levels of staff within the organisation took place prior to engagement of a designer.

The Case 2 organisation operated a number of older facilities and a process was established to form a committee with representatives from all areas of operation within the organisation to identify strengths and weaknesses that could be incorporated or avoided in the new facility. This process of consultation involved the election of a representative from each department or area of expertise within the operating facilities, these representatives formed a "Building Committee". Each "Building Committee" member sought input from the group they represented and the ideas were discussed at committee level. Ideas accepted by the "Building Committee" were then presented to the organisation's Board of Directors were the relevance and inherent advantage of the idea had to be defended. Throughout the consultation and Board approval process the "Building Committee" compiled a design brief which was ultimately presented to the designers. The result of this process lead to compatible positive responses from members of the care team and the organisation's management, in contrast to the remaining cases in the study, when asked about the origin of the building design concept.

The process of consultation and staff involvement continued into the construction phase with the "Building Committee" electing a subcommittee (known as the "Colour Team") which included the facility designer and was responsible for the selection of all internal furnishings and colour schemes.

\section{Discussion}

This paper deals with the benefits of a consultative design process but in doing so reaches back to the larger previous project which enabled cross case synthesis between projects derived from a process of "premature commitment" (Darke, 1979) and a project which underwent a process of detailed analysis during the design phase (Pati et al., 2012). The larger previous study identified the differences between the two approaches and highlighted a number of major advantages the consultative design process enabled. These advantages are as follows:

i) The lessons learnt from other facilities can be brought to the new facility. Unless a post occupancy evaluations are carried out this information is not available by adapting previous projects,

ii) Information about current work practices or accreditation and certification requirements are up to date. The risk of utilising superseded information is higher by adapting previous projects,

iii) "Premature commitment" could lead to designers not being aware of issues that are counterproductive to staff in their design. An example is the swing of doors into resident bathrooms which in RAC facilities should be counter the normal orientation of doors as a resident can fall against the door within a bathroom. Without consultative design these types of criticism have been found to be passed to subsequent projects.

iv) "Premature commitment" could lead to designers not being aware of changed community expectations or assessment requirements. An example is an early requirement for full view of the resident's bed from the corridor. Assessment requirements and community expectations have shifted to respect the resident's privacy and dignity above other issues. Without consultative design these types of criticism have been found to be passed to subsequent projects. 


\subsection{Consultative Design Process}

Comparing a consultative design process to the typical design process which can involve a degree of "premature commitment" has exposed three important steps. The three steps form an overarching design process and are shown in Figure 1 with the consultative project design pathway indicated as Scenario 2 where the influence of the care team as the building users can be seen throughout the process. The work stress/satisfaction of the care team is important in RAC facilities as they control quality of care which has been shown to be a major factor in the resident's quality of life (Murphy, 2007). The work stress/satisfaction of the care team also has an impact on social sustainability, reducing the resource footprint of the facility.

Scenario 1 in Figure 1 is included for comparison purposes and indicates the typical design process which includes the ability to adapt previous projects. Scenario 1 illustrates the possibility of care team input on commencement of the process and then habitation of the facility on completion. The dashed red lines in Scenario 1 indicate the path outlined by Brawne (1992), Darke (1979), Eckert \& Stacy (2000), Restrepo \& Christiaans (2004) and Visser (2006).

The ultimate aim of this overarching process is to provide the opportunity for optimal facility design. The three steps are as follows:

1. Management and Care Team establish specific requirements,

2. Preparation of a detailed and complete design brief which the organisation can confidently defend, and

3. Ensure a process of current project analysis and engagement.

4.
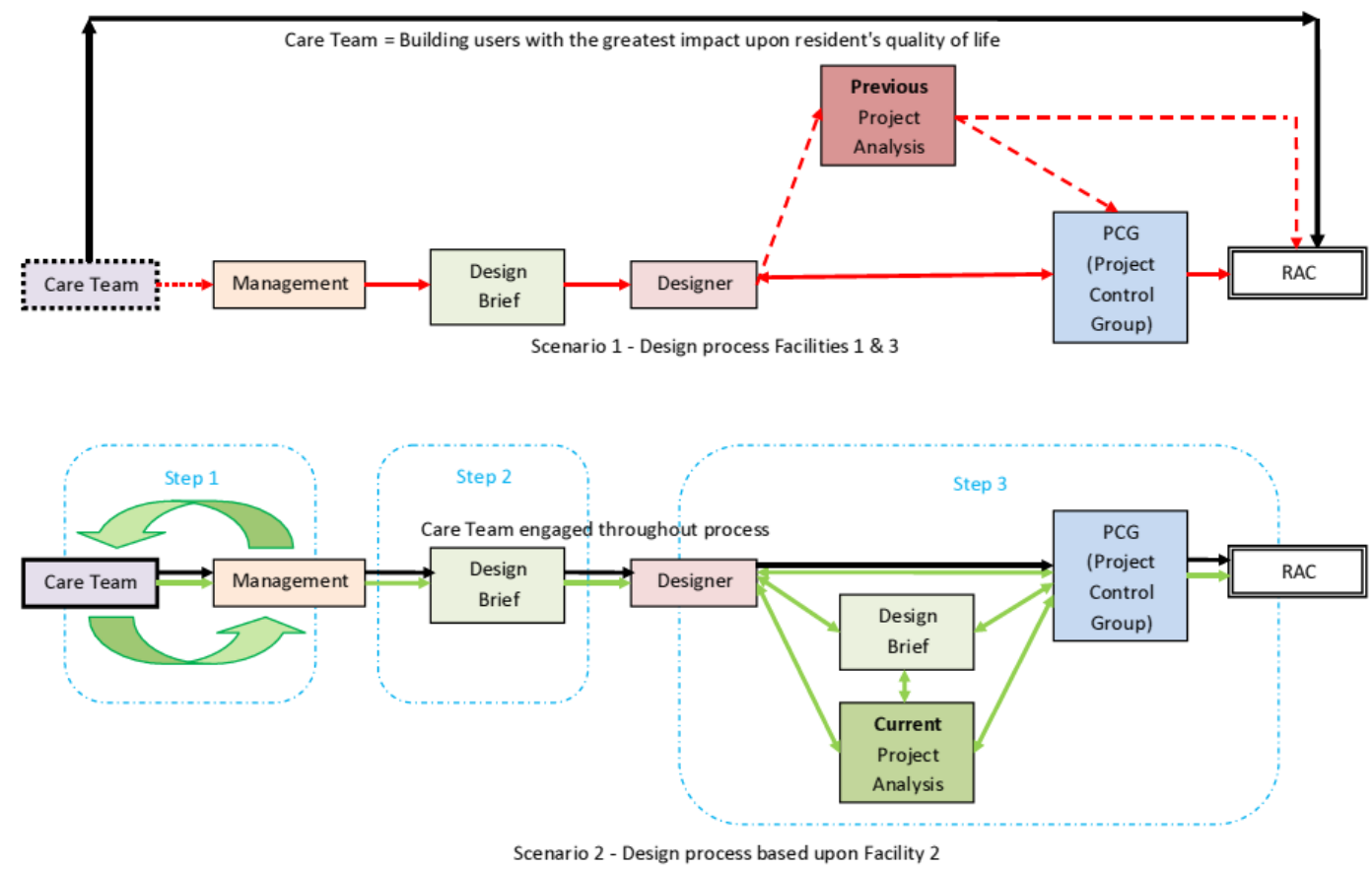

Figure 1: Overarching process to ensure optimal facility design. Scenario 2 shows the consultative design process with three steps required where Scenario 1 is included for comparison purposes. A discussion of these important steps follows: 


\section{Step 1. Establish specific requirements}

A wide ranging process of consultation carried out with all project stakeholders before designers are appointed will result in widespread education of all stakeholders in the facility's operations and an understanding between the diverse groups (e.g. Care Team, kitchen, maintenance, administration etc) that contribute to an RAC organisation. The suitability of concepts raised during this process will be further confirmed by presentation, defence and approval at the organisation's board level. The establishment of specific requirements in this way engages a hybrid process of analysis, synthesis and evaluation (Lawson, 2005) and assimilation, study, development (RIBA, 1980). This hybrid process when undertaken by the organisation has been shown to establish a strict range of specific requirements for a new facility leading to a more definite brief. The understandings and confidence gained from this process serves to underpin the ensuing steps in the project delivery.

\section{Step 2. Preparation of a detailed and complete design brief that the organisation can confidently defend}

The widespread process of consultation, analysis, justification and evaluation with all levels of staff within the organisation enables building users to take ownership of the design of the facility (Jensen, 2011; Nutt, 1993) and have a confidence that their design incorporates the optimal design solution of the time. With Case 2 in the wider study, the process enabled two very important eventualities:

i) the process enables a complete and detailed design brief which serves to remove many grey areas in the design (Smith et al., 2001), and

ii) the confidence and knowledge that the whole organisation has selected particular aspects of the design should reinforce the determination of the organisation's representatives on the design team to ensure the carefully selected aspects are included in the design (Chandra \& Loosemore, 2011).

This second aspect is important and goes towards eliminating the argument from both designers and stakeholders that they have been ignored by the other (Bakker, 2000; Bogers, Meel, \& Voordt, 2008) With Case 2 the confidence gained by the process adopted in Step 1 served to underpinned Step 2 and empowered the organisation's representatives to ensure the specific requirements identified as necessary for the facility were incorporated into the project design.

\section{Step 3. Ensure a process of current project analysis and engagement}

The third critical step is to avoid the model described by Darke (1979) and other authors like Restrepo \& Christiaans (2004) Visser (2006), Ball and Ormerod (2000), Ball, Evans and Dennis (1994), Goel (1995) and Cross (2001) as "generator - conjecture - analysis" or a derivation thereof. The model reduces analysis and evaluation in the design process to a somewhat limited range based on recent projects. The "generator - conjecture - analysis" model has been associated with perpetuating several inappropriate and untested aspects of RAC facility design (Hilaire, 2016). Again the experience with Case 2 saw the circumvention of the "generator - conjecture - analysis" route which was assisted by the confidence provided by the wide ranging process of consultation involving 
all levels of stakeholders. The consultative process culminated in approval by the Board of Directors and thus the organisation's representatives on the design team were empowered to insist on alternative solutions to design problems which enabled the design team to analyse, synthesis and evaluate the optimal proposition to satisfy the detailed design brief.

\section{Conclusion}

This paper has reported on the influence of consultative design in RAC which was identified in a larger two stage multi case study of design influences in RAC. The process of consultative design has been shown in Case 2 of the previous study to address stakeholder requirements providing widespread acceptance of the facility and thereby providing a step towards optimising the care team's work stress/satisfaction. Work stress/satisfaction in RAC has been shown to have an impact on quality of care which in turn has the potential to have an effect on the quality of life of residents and address aspects of social sustainability.

Incorporating consultative design into the design process in RAC has demonstrated an ability to incorporate stake holder requirements thereby providing the opportunity to:

i) Apply experiences from other facilities to the new facility,

ii) Update facilities to accommodate current work practices or accreditation and certification requirements,

iii) Reduce the instance of incorporating issues that are counterproductive to staff in the facility design, and

iv) Remain abreast of changed community expectations and/or assessment requirements.

Consultative design has been shown to provide opportunities that reduce the instance of various forms of "premature commitment" whilst affording a greater chance of the built environment satisfying user requirements by enabling:

i) An accurate brief,

ii) Confident administration of the brief from the building owner's side, and

iii) Ongoing detailed analysis of requirements.

To achieve the objective of this paper an alternative model for the design process to optimise facility design has been presented. This model reduces the reliance on design conjecture or "premature commitment" (Darke 1979) In addition consultative design incorporates the opportunity for facility stakeholders to address work stress/satisfaction and adjust the facility to improve the "environmental fit" of facility users (Vischer, 2007). Improvement of the environmental fit has the potential to benefit all stakeholders within the RAC environment.

\section{References}

Alimoglua, M. K., \& Donmezb, L. (2005). Daylight exposure and the other predictors of burnout among nurses in a University Hospital. International Journal of Nursing Studies, 42(5), 549555.

Aspinall, P. (2001). Building Behaviour. Building Services Engineering Research \& Technology, 22(1), 34-46.

Bakker, R. (2000). Facility design: Getting it right the first time. Nursing Homes Long Term Care Management, 49(11), 68-71. 
Ball, L. J., Evans, B. T., \& Dennis, I. (1994). Cognitive processes in engineering design: a longitudinal study. Ergonomics, 37(11), 1753-1786.

Ball, L. J., \& Ormerod, T. C. (2000). Putting ethnography to work: the case for a cognitive ethnography of design. International Journal of Human-Computer Studies in Higher Education, 53(1), 147-158.

Bogers, T., Meel, J. J. v., \& Voordt, T. J. v. d. (2008). Architects about briefing Recommendations to improve communication between clients and architects. Facilities, 26(3/4), 109-116.

Brawne, M. (1992). From Idea to Building: Issues in Architecture. Oxford: Butterworth-Heinemann.

Castle, N. (2007). Assessing Job Satisfaction of Nurse Aides in Nursing Homes. Journal of Gerontological Nursing, 33(5), 41-47.

Cross, N. (2011). Design thinking: understanding how designers think and work. Oxford: Berg Publishers.

Darke, J. (1979). The primary generator and the design process Design Studies, 1(1), 36-44.

Eckert, C., \& Stacey, M. (2000). Sources of inspiration: a language of design. Design Studies, 21(5), 523-538.

Edvardsson, D., Sandman, P.-O., Nay, R., \& Karlsson, S. (2009). Predictors of job strain in residential dementia care nursing staff. Journal of Nursing Management, 17, 59-65.

Goel, V. (1995). Sketches of thought. Cambridge, MA: MIT Press.

Hannan, S., Norman, I. J., \& Redfern, S. J. (2001). Care work and quality of care for older people: a review of the research literature. Reviews in Clinical Gerontology, 11, 189-203.

Hilaire, T. J. (2016). Sustainable residential aged care: The influence of the built environment on carer work satisfaction and stress (PhD), University of Newcastle, Newcastle NSW.

Murphy, K. (2007). Nurses' perceptions of quality and the factors that affect quality care for older people living in long-term care settings in Ireland. Journal of Clinical Nursing, 16, 873-884.

Pati, D., Harvey, T. E., \& Thurston, T. (2012). Estimating Design Impact on Waste Reduction: Examining Decentralized Nursing. Journal of Nursing Administration, 42(11), 513-518.

Restrepo, J., \& Christiaans, H. (2004). Problem Structuring and Information Access in Design. Journal of Design Research, 4(2).

Sinoo, M. M., Hoof, J. v., \& Kort, H. S. M. (2011). Light conditions for older adults in the nursing home: Assessment of environmental illuminances and colour temperature. Building and Environment, 46, 1917-1927.

Spanbroek, N. (2005). Design Profession and Ageing in Place. Australasian Journal on Ageing, 24(2), 69-70.

Vischer, J. C. (2007). The effects of the physical environment on job performance: towards a theoretical model of workspace stress. Stress and Health, 23, 175-184.

Visser, W. (2006). Designing as Construction of Representations: A Dynamic Viewpoint in Cognitive Design Research. Human-Computer Interaction, 21(1), 103-152. 